\title{
Complete spore-cortex hydrolysis during germination of Bacillus subtilis 168 requires SleB and YpeB
}

Department of Molecular Biology and

Biotechnology, University of Sheffield, Firth Court, Western Bank, Sheffield S10 2TN, UK

\author{
Fiona M. Boland, Abdelmadjid Atrih, Haridasan Chirakkal, \\ Simon J. Foster and Anne Moir
}

Author for correspondence: Simon J. Foster. Tel: +44 114222 4411. Fax: +44 1142728697. e-mail: S.Foster@sheffield.ac.uk

\begin{abstract}
The role of the sleB gene of Bacillus subtilis, which encodes a putative sporecortex-lytic enzyme, and the downstream ypeB gene were investigated. Both SleB and YpeB were required for normal germination to occur. The corresponding mutants formed phase-bright, heat-resistant spores with no apparent defects in dormancy. However, mutant spore suspensions lost optical density slower than the wild-type and spores were phase-grey even $12 \mathrm{~h}$ after the triggering of germination. Since the loss of heat resistance and release of dipicolinic acid was similar to the wild-type, these mutants were blocked in the later stages of germination. The mutants were nevertheless capable of outgrowth on rich agar to form colonies, indicating that other spore components can compensate for their function sufficiently to allow outgrowth. The expression and regulation of the operon was examined using a lacz transcriptional fusion. Expression of the operon began $\mathbf{2} \mathrm{h}$ after the onset of sporulation and was under the control of RNA polymerase containing the forespore-specific sigma factor, $\sigma^{\mathrm{G}}$. The application of reverse phase HPLC revealed that the mutants do not have any structural defect in the dormant spore cortex and therefore these genes are not required for normal sporecortex synthesis. The analysis of peptidoglycan dynamics during germination showed, however, that the cortex was only partially hydrolysed in both mutants. This analysis also revealed that the likely hydrolytic bond specificity of SleB is likely to be that of a lytic transglycosylase.
\end{abstract}

Keywords: Bacillus subtilis, endospores, germination, peptidoglycan, cortex hydrolysis

\section{INTRODUCTION}

The formation of resistant dormant endospores is a survival strategy used by members of the genera Bacillus and Clostridium during nutrient deprivation. The spore cortex maintains heat resistance and dormancy (Ellar, 1978). The cortex consists of a thick layer of peptidoglycan with a unique spore-specific structure (Atrih et al., 1996; Popham et al., 1996a). Hydrolysis of the cortex peptidoglycan is essential for later germination events and outgrowth (Atrih \& Foster, 1999; Atrih et al., 1998; Popham et al., 1996b).

A number of spore-cortex-lytic enzymes have been

Abbreviations: GSLE, germination-specific lytic enzyme; MUG, methylumbelliferyl $\beta$-D-galactoside; RP-HPLC, reverse phase HPLC. isolated from spores of different organisms. Two lytic enzymes have been isolated from Clostridium perfringens S40 spores - a $31 \mathrm{kDa}$ enzyme encoded by the gene sleC (Miyata et al., 1995) and a $38 \mathrm{kDa}$ enzyme encoded by the gene sleM (Chen et al., 1997). The Bacillus cereus IFO 13597 gene sleB encodes a $24 \mathrm{kDa}$ enzyme (Makino et al., 1994; Moriyama et al., 1996b), and its homologue has been identified and inactivated in Bacillus subtilis. The resulting mutant germinates slower than the wild-type (Moriyama et al., 1996a).

Foster \& Johnstone (1987) isolated a germinationspecific lytic enzyme (GSLE) that was capable of cortex hydrolysis from the spores of Bacillus megaterium KM. The enzyme was activated in vivo during germination and has a high specificity for intact spore cortex. Western blot analysis revealed cross-reactivity with proteins from spore fractions of other species and that the enzyme was 
capable of germinating permeabilized spores of other species (Foster \& Johnstone, 1988).

The recent application of reverse phase HPLC (RPHPLC) to monitor peptidoglycan structural dynamics during the germination of $B$. subtilis revealed that the mechanism of cortex hydrolysis is complex and involves several hydrolases of differing specificity (Atrih et al., 1998).

In $B$. subtilis, the sle $B$ and adjacent downstream ypeB gene form a bicistronic operon (Moriyama et al., 1999). In this study, we have shown that a defect in either the $s l e B$ or the $y p e B$ genes results in incomplete germination. Analysis of cortex dynamics during germination revealed the likely hydrolytic bond specificity of SleB.

\section{METHODS}

Bacterial strains, growth and preparation of spores. All $B$. subtilis strains used in this study are shown in Table 1. Mutations were transferred into the laboratory wild-type background (HR) used for muropeptide analysis (Atrih et al., 1996). Vegetative cells of B. subtilis were grown in nutrient broth (Oxoid) or on nutrient agar plates. Plasmids were constructed in, and prepared from, Escherichia coli strain TG1 grown in Luria-Bertani (LB) broth or on LB agar. When appropriate, chromosomal drug resistance markers in $B$. subtilis were selected with chloramphenicol $\left(5 \mu \mathrm{g} \mathrm{ml} \mathrm{m}^{-1}\right)$, kanamycin $\left(10 \mu \mathrm{g} \mathrm{ml}^{-1}\right)$, or erythromycin $\left(1 \mu \mathrm{g} \mathrm{ml}^{-1}\right)$ and lincomycin $\left(25 \mu \mathrm{g} \mathrm{ml}^{-1}\right)$. All bacterial cultures were grown at $37^{\circ} \mathrm{C}$.

\section{Construction of mutants insertionally inactivated in sleB or ypeB}

(i) Plasmid construction. Plasmids pFB101 and pFB102 were made by cloning internal fragments of the sle $B$ and $y p e B$ genes, respectively, into pMUTin2 (Vagner et al., 1998) using nucleotide sequence from the $B$. subtilis complete genome sequence (Kunst et al., 1997). Genomic DNA was used as template in the PCR amplification of the $250 \mathrm{bp}$ internal fragment of sleB using the forward primer (5'-GCCGAAGCTT $A_{64}$ TTAATACTGAAACGATCTC $\left.{ }_{83}\right)$ and the reverse primer $\left(5^{\prime}\right.$-CGCGGATCC ${ }_{294}$ ATTAAGGTTTGCTT-

Table 1. Bacterial strains and plasmids

\begin{tabular}{|c|c|c|}
\hline Strain or plasmid & Genotype* & Source or reference $†$ \\
\hline \multicolumn{3}{|l|}{ Strains } \\
\hline $168 \mathrm{HR}$ & $\operatorname{trp} C 2$ & Laboratory stock \\
\hline FB101 & $\operatorname{trp} C 2$ sleB-lacZ, $\mathrm{Em}^{\mathrm{r}}$ & $(\mathrm{pFB} 101) \rightarrow 168 \mathrm{HR}$ \\
\hline FB102 & $\operatorname{trp} C 2$ ypeB-lacZ, $\mathrm{Em}^{\mathrm{r}}$ & $(\mathrm{pFB} 102) \rightarrow 168 \mathrm{HR}$ \\
\hline FB103 & $\operatorname{trpC2}$ spoIIGB::kan sleB-lacZ, $\mathrm{Em}^{\mathrm{r}} \mathrm{Km}^{\mathrm{r}}$ & $(1295) \rightarrow$ FB101 \\
\hline FB104 & $\operatorname{trp} C 2$ spolIAABC::cat sleB-lacZ, $\mathrm{Em}^{\mathrm{r}} \mathrm{Cm}^{\mathrm{r}}$ & $(\mathrm{JE} 650) \rightarrow \mathrm{FB} 101$ \\
\hline FB105 & trpC2 spoIIIG::kan sleB-lacZ, $\mathrm{Em}^{\mathrm{r}} \mathrm{Km}^{\mathrm{r}}$ & $(1296) \rightarrow$ FB101 \\
\hline FB106 & $\operatorname{trp} C 2$ spolliC ::cat sleB-lacZ, $\mathrm{Em}^{\mathrm{r}} \mathrm{Km}^{\mathrm{r}}$ & $(618) \rightarrow$ FB101 \\
\hline FB107 & $\operatorname{trp} C 2$ Pspac-sigE sleB-lacZ, $\mathrm{Em}^{\mathrm{r}} \mathrm{Km}^{\mathrm{r}}$ & $(\mathrm{pDG} 180) \rightarrow \mathrm{FB} 101$ \\
\hline FB108 & $\operatorname{trpC2} \mathrm{P}$ spac-sigF sleB-lacZ, $\mathrm{Em}^{\mathrm{r}} \mathrm{Cm}^{\mathrm{r}}$ & $(\mathrm{pRS} 11) \rightarrow \mathrm{FB} 101$ \\
\hline FB109 & $\operatorname{trp} C 2$ Pspac-sigG sleB-lacZ, $\mathrm{Em}^{\mathrm{r}} \mathrm{Km}^{\mathrm{r}}$ & $(\mathrm{pDG} 298) \rightarrow \mathrm{FB} 101$ \\
\hline FB110 & $\operatorname{trp} C 2$ Pspac-sigK sleB-lacZ, $\mathrm{Em}^{\mathrm{r}} \mathrm{Cm}^{\mathrm{r}}$ & $(\mathrm{SH} 132) \rightarrow$ FB101 \\
\hline HC145 & $\operatorname{trp} C 2$ sle $B \Delta$ & $(\mathrm{pGSB} 21) \rightarrow 168 \mathrm{HR}$ \\
\hline SH132 & $\operatorname{sig} K \Delta 19:: p V O 12(\mathrm{P} s p a c-s i g K), \mathrm{Cm}^{\mathrm{r}}$ & Oke \& Losick (1993) \\
\hline 1295 & $\operatorname{trpC2}$ spollGB::kan, $\mathrm{Km}^{\mathrm{r}}$ & $\begin{array}{l}\text { J. Errington, Oxford } \\
\text { University, UK }\end{array}$ \\
\hline 650 & $\operatorname{trp} C 2$ ilvB2 leuB16 spoll AABC::cat, $\mathrm{Cm}^{\mathrm{r}}$ & $\begin{array}{l}\text { J. Errington, Oxford } \\
\text { University, UK }\end{array}$ \\
\hline 618 & $\operatorname{trp} C 2$ spollIC: : cat, $\mathrm{Cm}^{\mathrm{r}}$ & Turner et al. (1986) \\
\hline 1296 & $\operatorname{trpC2}$ spollIG::kan, $\mathrm{Km}^{\mathrm{r}}$ & $\begin{array}{l}\text { J. Errington, Oxford } \\
\text { University, UK }\end{array}$ \\
\hline \multicolumn{3}{|l|}{ Plasmids } \\
\hline pFB101 & sleB-lacZ & This study \\
\hline pFB102 & ypeB-lacZ & This study \\
\hline pGSB21 & sleB $\Delta$ & This study \\
\hline pRS11 & Pspac-sigF & $\begin{array}{l}\text { R. Schmidt, Harvard } \\
\text { University, USA }\end{array}$ \\
\hline pDG180 & Pspac-sigE & Popham \& Stragier (1991) \\
\hline pDG298 & Pspac-sigG & Sun et al. (1989) \\
\hline
\end{tabular}

$* \mathrm{Cm}^{\mathrm{r}}$, chloramphenicol resistance; $\mathrm{Km}^{\mathrm{r}}$, kanamycin resistance; $\mathrm{Em}^{\mathrm{r}}$, erythromycin resistance. †DNA transformation crosses are indicated; DNA source is in brackets and the arrow points to the recipient strain. 
$\left.T G_{278}\right)$ where the internal sequence of the gene is italicized (numbering is with respect to the A of the translational start codon of the gene) and the HindIII site of the forward primer and the $B a m \mathrm{HI}$ site of the reverse primer are underlined. The primers $\left(5^{\prime}\right.$-GCCGAAGCTTC ${ }_{157}$ TTCATGATAAAAT$\left.C G G_{173}\right)$ and $\left(5^{\prime}\right.$-CGCGGATCCA ${ }_{408}$ TATAGCTTATTTAG$T_{393}$ ) were used to amplify a $271 \mathrm{bp}$ segment of the $y p e B$ gene. pMUTin2 and the PCR fragments were digested with HindIII and $\mathrm{Bam} \mathrm{HI}$ and then ligated by the method of Sambrook et al. (1989).

(ii) Transformation of $E$. coli and B. subtilis. Transformation of $E$. coli was performed as described by Hanahan (1983). Transformation of $B$. subtilis 168 with pFB101 and pFB102 was performed by the competent cell method (Anagnostopoulos $\&$ Spizizen, 1961). Disruption of the sleB and $y p e B$ genes by means of Campbell-type recombination was confirmed by Southern blot analysis, using the appropriate plasmid as probe. Hybridization, probe labelling and detection were done with the Boehringer Mannheim nonradioactive DNA labelling and detection kit.

Construction of sle $B$ in-frame deletion mutant. To construct an in-frame deletion of sleB, a $5.6 \mathrm{~kb}$ DNA fragment spanning the sle $B$ and $y p e B$ coding sequence was synthesized by PCR using $B$. subtilis HR chromosomal DNA as template. Primers 5'-ATGCGAGCTC ${ }_{2640}$ CGGCTAAGAAGAGAGG-

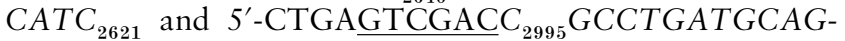
TATTGAAG ${ }_{3014}$ were used as forward and reverse primers, respectively (the chromosomal sequences are italicized and the SacI and SalI restriction sites added are underlined; the numbering is with respect to the A of the translational start codon of sleB). The PCR product was cloned in E. coli DH5 $\alpha$ using plasmid pGEM3Z, after appropriate restriction digestion and ligation. A recombinant plasmid, pGSB1 containing the cloned DNA was isolated and this was used as template DNA for inverse-PCR using primers 5'-ATGCGGATCC $G_{843}$ ATACGGCTACAAGTCCGTG ${ }_{824}$ and 5'-ATGA GGATCCC $_{444}$ TGCCGTGCTTCTGCTTGTTG $_{464}$ as forward and reverse primers, respectively (the chromosomal sequences are italicized and the restriction site for $\mathrm{BamHI}$ is underlined). The PCR product from this experiment resulted in a deletion of 399 bases in the coding region of the sle $B$ gene, removing amino acid residues $148-281$ of SleB. The PCR product was then restricted with $\mathrm{BamHI}$ and religated before transformation into E. coli $\mathrm{DH} 5 \alpha$. A plasmid, pGSB21, carrying the sleB deletion was isolated and verified by restriction analysis. The sleB deletion was then transferred into $B$. subtilis HR by congression using pGSB21 linearized with $S c a I$ and $t r p^{+}$DNA. Congressant colonies $\left(t r p^{+}\right)$were selected on SS minimal agar and then screened by PCR for the sleB deletion. One congressant, which showed the correct deletion, was verified by Southern blot and named HC145.

Spore preparation and germination. Sporulation was initiated in CCY medium and spores of B. subtilis were prepared as described by Stewart et al. (1981). Spores were stored at a concentration of $10 \mathrm{mg}$ dry weight $\mathrm{ml}^{-1}$ in distilled water at $-20{ }^{\circ} \mathrm{C}$. Purified spores were heat-activated at $70^{\circ} \mathrm{C}$ for $30 \mathrm{~min}$ and cooled in ice. Germination was initiated by the addition of L-alanine to a final concentration of $1 \mathrm{mM}$, or by the addition of asparagine to $30 \mathrm{mM}$ with glucose and fructose each to a concentration of $5.6 \mathrm{mM}$ (AGF). Germinant was added to a $5 \mathrm{mg}$ dry weight $\mathrm{ml}^{-1}$ spore suspension in $10 \mathrm{mM}$ Tris/ $\mathrm{HCl} \mathrm{pH} 7$ containing $\mathrm{KCl}\left(10 \mathrm{mg} \mathrm{ml}^{-1}\right)$. Spores were germinated at $37^{\circ} \mathrm{C}$ and the extent of germination was monitored by recording the decrease in $\mathrm{OD}_{600}$ (Foster \&
Johnstone, 1987) over a $2 \mathrm{~h}$ period. Phase-darkening of spores was determined by phase-contrast microscopy.

(i) Determination of loss of heat resistance during germination. Germinating spore samples were diluted serially in $10 \mathrm{mM}$ Dalanine and incubated at $70{ }^{\circ} \mathrm{C}$ for $30 \mathrm{~min}$. After cooling in ice, viability was measured by plate counting on nutrient agar.

(ii) Measurement of loss of dipicolinic acid during germination. Samples of germination spore suspension $(3 \mathrm{ml})$ were filtered through a $0.45 \mu \mathrm{m}$ membrane and the dipicolinic acid content was measured as described by Scott \& Ellar (1978).

RP-HPLC analysis of spore peptidoglycan. Cortex extraction from dormant and germinated spores, muropeptide separation by RP-HPLC, and amino acid and mass spectrometry analyses were performed as previously described (Atrih et al., 1996, 1998).

\section{Analysis of gene expression}

(i) Expression under the control of the Pspac promoter. Induced expression of sigma factor genes under the control of Pspac was carried out by adding IPTG $(400 \mu \mathrm{M}$ final concentration) to cells growing in LB at an $\mathrm{OD}_{600}$ of $0 \cdot 25$ (Sun et al., 1989).

(ii) Expression during sporulation. Synchronous sporulation was performed by the resuspension method of Sterlini \& Mandelstam (1969). Samples were harvested every hour after the initiation of sporulation $\left(t_{0}\right)$ for $8 \mathrm{~h}$ and sporulation morphology was monitored by microscopy.

(iii) Measurement of $\beta$-galactosidase activity. $\beta$-Galactosidase assays, using MUG (methylumbelliferyl $\beta$-D-galactoside) as the substrate, were performed as described by Youngman (1990), except that cells were permeabilized by incubation with lysozyme on ice for $20 \mathrm{~min}$, MUG was used at a final concentration of $600 \mu \mathrm{g} \mathrm{ml}^{-1}$ in DMSO and the assay was incubated at $28^{\circ} \mathrm{C}$. Fluorescence was measured on a fluorometer (Hoefer). One unit of $\beta$-galactosidase activity was defined as the amount of enzyme which releases $1 \mathrm{pmol}$ methylumbelliferone $\min ^{-1} \mathrm{ml}^{-1}$ (Zuberi et al., 1987), normalized to a culture $\mathrm{OD}_{600}$ of $1 \cdot 0$.

\section{RESULTS}

\section{Characterization of the germination response of $s / e B$ and ype $B$ mutants}

B. subtilis strains FB101 and FB102 contain an sleB-lacZ and a $y p e B-l a c Z$ transcriptional fusion, respectively, which resulted in insertional inactivation of the $s l e B$ and $y p e B$ genes. An in-frame deletion in $s l e B$ was constructed to give strain HC145. In HC145, YpeB could still be produced in the absence of active SleB. All strains showed comparable sporulation efficiency to the parent. Spores prepared from these mutant strains were phasebright and heat-resistant $\left(70{ }^{\circ} \mathrm{C}, 30 \mathrm{~min}\right)$. During Lalanine-triggered germination, wild-type spores lost $55-60 \%$ of their initial optical density and became phase-dark, whereas mutant strains FB101 (sleB), FB102 $(y p e B)$ and HC145 (sleBs) lost optical density at a slower rate, and became phase-grey (Fig. 1 and data not shown). Thus both SleB and YpeB are necessary for the germination process to occur normally. Similar results were obtained when germination was triggered in AGF (data not shown), suggesting that both $s l e B$ and $y p e B$ are also required for the AGF germination pathway. 


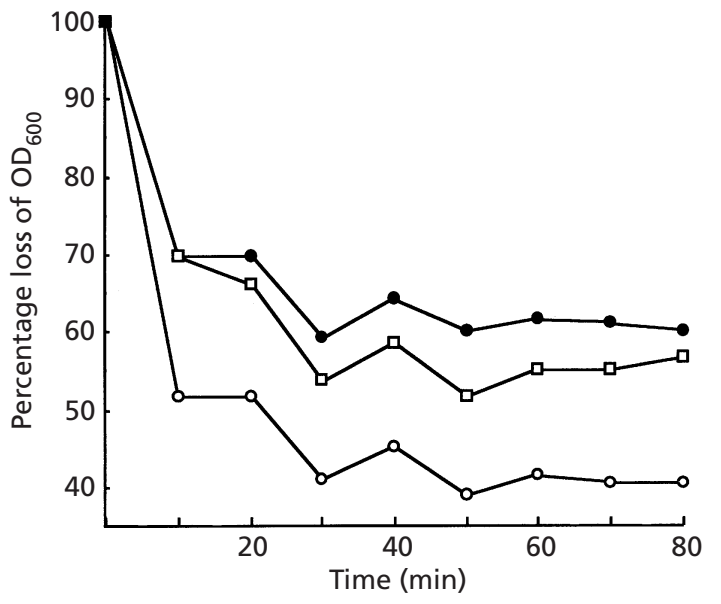

Fig. 1. Spore germination of $B$. subtilis HR (wild-type, $\bigcirc$ ), FB101 $(s / e B, 0), \mathrm{FB} 102$ (ypeB, $\square$ ). Germination was monitored by measurement of $\mathrm{OD}_{600}$ at the times indicated after addition of $1 \mathrm{mM}$ L-alanine and is expressed as the percentage loss of initial optical density.

The loss of heat resistance and the release of DPA during germination of strains FB101 (sleB), FB102 (ypeB) and HC145 (sleBA) were comparable to the wild-type (data not shown) in two independent experiments, indicating that these mutants are blocked in the later stages of germination.

The germinated spores from the mutant strains, in germination buffer, remained phase-grey even $12 \mathrm{~h}$ after germination was triggered. Strains FB101 (sleB), FB102 $(y p e B)$ and HC145 (sleBA) were, however, capable of outgrowth to form colonies when plated on nutrient agar overnight at $37^{\circ} \mathrm{C}$, indicating that B. subtilis can overcome the loss of SleB and/or YpeB to outgrow to form a new vegetative cell.

\section{Peptidoglycan structural analysis of dormant spores}

To determine whether the germination defect in the sleB and $y p e B$ mutants is caused by a structural modification of spore peptidoglycan, the RP-HPLC profiles of Cellosyl-digested peptidoglycan from these mutants were compared to that of the wild-type. No peptidoglycan structural defect could be detected in strains FB101 (sleB), FB102 (ypeB) and HC145 (sleBs) compared to the wild-type (data not shown). The sleB and $y p e B$ gene products are both likely therefore to be involved in the processes associated with cortex hydrolysis during germination.

(i) Peptidoglycan dynamics during germination. RP-HPLC profiles of germinated-spore-associated peptidoglycan in the wild-type and FB101 (sleB) are shown in Fig. 2 (a) and 2 (b), respectively. After $2 \mathrm{~h}$ germination, the ratio of dormant spore muropeptides and germinationassociated muropeptides was altered between the wildtype (HR; Fig. 2a) and strain FB101 (sleB; Fig. 2b). In strain FB101 (sleB) there were less germination muro-
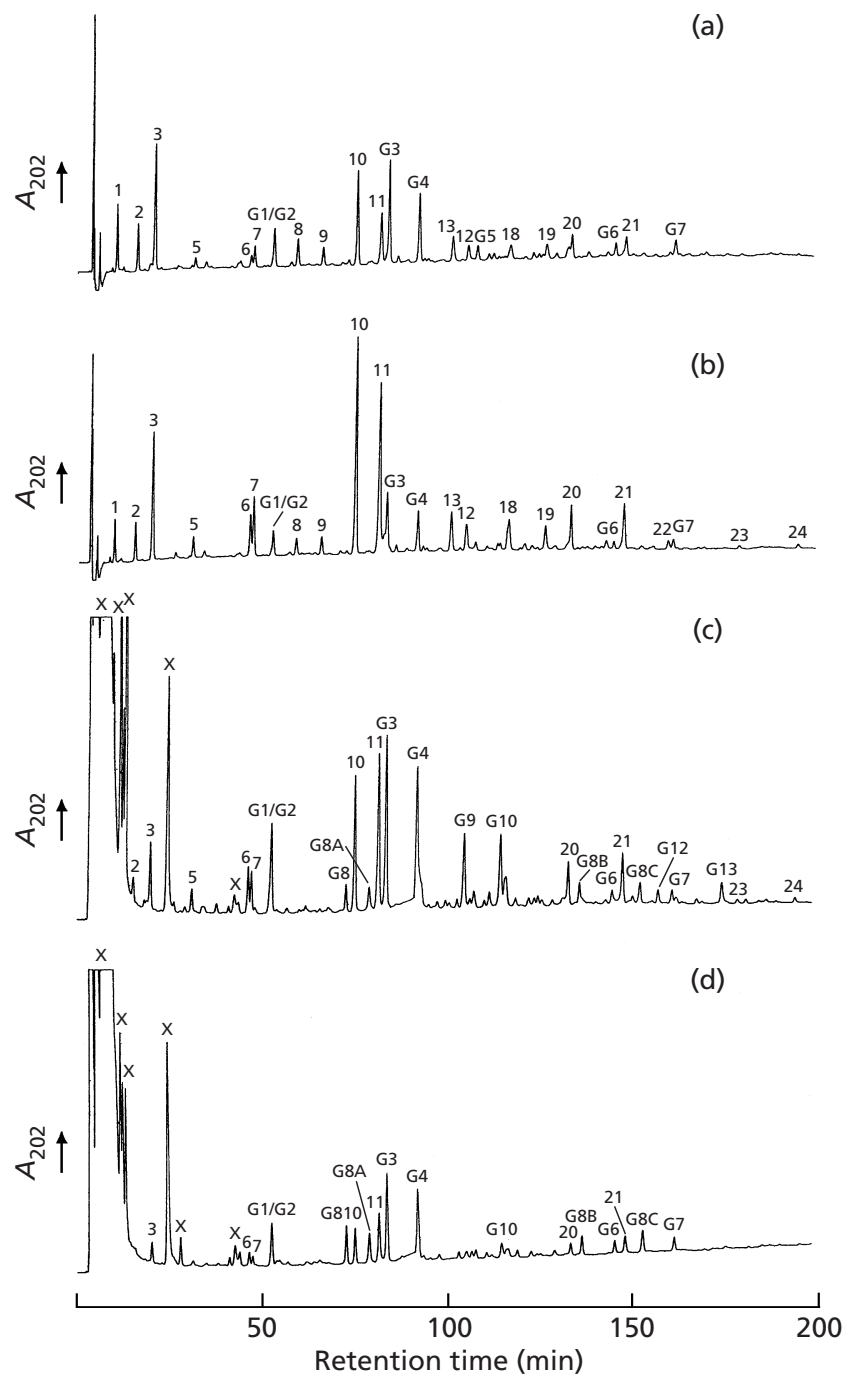

Fig. 2. Analysis of muropeptides by RP-HPLC during germination of $B$. subtilis 168 HR spores. Muropeptidecontaining samples were taken after $2 \mathrm{~h}$ germination and separated by RP-HPLC and the $A_{202}$ of the eluates monitored. (a) $B$. subtilis HR germinated-spore-associated material; (b) FB101 (sleB) germinated-spore-associated material; (c) germination exudate from $\mathrm{HR}$; and (d) germination exudate from $\mathrm{FB} 101(s / e B)$.

peptides (G1-G7) and correspondingly more dormant spore muropeptides $(10,11,20,21)$. Strains FB102 (ypeB) and HC145 (sleBA) showed identical profiles to strain FB101 (sleB) (data not shown). This result indicates a partial hydrolysis of the cortex in the sleB mutant. The amount of peptidoglycan released, calculated as the ratio of retained material to that of primordial cell wall (muropeptides 1 and 8 ) at time 0 and after $2 \mathrm{~h}$ germination, for strains FB101 (sleB), and FB102 (ypeB) was $44 \%$ and $38 \%$, respectively. This amount is approximately $20 \%$ lower than that released from the wild-type, where $64 \%$ of peptidoglycan fragments were released in the germination exudate after $2 \mathrm{~h}$. 
Table 2. Calculated and observed $\mathrm{m} / \mathrm{z}$ values for protonated sodiated and deprotonated molecular ions of new muropeptides from germination exudate of FB101 (s/eB)

\begin{tabular}{|llrrrr|}
\hline \multirow{2}{*}{ Muropeptide $^{*}$} & Ion & \multicolumn{2}{c}{$\boldsymbol{m} / \boldsymbol{z}$} & $\boldsymbol{m}$ (Da) $\dagger$ & Identity \\
\cline { 3 - 5 } & & Observed & Calculated & & \\
\hline \multirow{2}{*}{ G8A } & {$[\mathrm{M}+\mathrm{H}]^{+}$} & $785 \cdot 9$ & $989 \cdot 0$ & $\mathbf{- 2 0 3 \cdot 1}$ & Trisaccharide alanine \\
& {$[\mathrm{M}-\mathrm{H}]^{-}$} & $783 \cdot 3$ & $987 \cdot 0$ & $\mathbf{- 2 0 3 \cdot 7}$ & \\
G8B & {$[\mathrm{M}+\mathrm{Na}]^{+}$} & $1600 \cdot 0$ & $1801 \cdot 7$ & $\mathbf{- 2 0 1 \cdot 7}$ & Pentasaccharide tetrapeptide \\
& {$[\mathrm{M}-\mathrm{H}]^{-}$} & $1575 \cdot 9$ & $1777 \cdot 7$ & $\mathbf{- 2 0 2 \cdot 8}$ & \\
G8C & {$[\mathrm{M}+\mathrm{Na}]^{+}$} & $1227 \cdot 7$ & $1429 \cdot 4$ & $\mathbf{- 2 0 1 \cdot 7}$ & Pentasaccharide alanine \\
& {$[\mathrm{M}-\mathrm{H}]^{-}$} & $1203 \cdot 2$ & $1405 \cdot 4$ & $\mathbf{- 2 0 2 \cdot 2}$ & \\
\hline
\end{tabular}

* Muropeptides as numbered in Fig. 2(c) and 2(d).

†Difference between observed and calculated protonated, sodiated or deprotonated molecular mass values. Boldface characters denote deviations where the calculated values are the most likely combinations of the substituent components.

(ii) Germination exudate. The RP-HPLC profiles of germination exudate of the wild-type and the sle $B$ mutant are shown in Fig. 2(c) and 2(d), respectively. The first impression from the RP-HPLC muropeptide profile of strain FB101 $(s l e B)$ is the relative abundance of muropeptides G8, G8A, G8B and G8C compared to the wild-type. Muropeptide G8 has been previously identified as a trisaccharide tetrapeptide (Atrih et al., 1998). The muropeptides G8A, G8B and G8C are present in the wild-type, but they are produced in substantial amounts in the sle $B$ mutant only. Amino acid analysis and mass spectrometry revealed that muropeptides $\mathrm{G} 8 \mathrm{~A}$, G8B and G8C are trisaccharide alanine, pentasaccharide tetrapeptide and pentasaccharide alanine, respectively (Table 2). These muropeptides are therefore the products of an $N$-acetylglucosaminidase already suggested to be involved in cortex hydrolysis during germination of B. subtilis endospores (Atrih et al., 1998). The most striking difference in the peptidoglycan RPHPLC profile of strain FB101 (sleB) compared to the wild-type is the apparent absence of muropeptides G9, G10, G12 and G13 (all are reduced by $>90 \%$ compared to background levels). These muropeptides have previously been identified as anhydromuropeptides generated by a lytic transglycosylase (Atrih et al., 1998). The RP-HPLC profile of peptidoglycan fragments from germination exudates of strains FB101 (sleB), FB102 $(y p e B)$ and $\mathrm{HC} 145$ (sleB $\Delta)$ mutants are similar, suggesting the important role of the gene products in cortex hydrolysis during germination.

\section{Expression of sleB during sporulation}

Synchronous sporulation of the mutant strains was induced by the resuspension method and $\beta$-galactosidase activity from the sleB-lacZ and $y p e B-l a c Z$ transcriptional fusions was measured. In both cases, activity was first detected between $t_{2}$ and $t_{3}(2-3 \mathrm{~h}$ after the onset of sporulation, after asymmetric septation) and was maximal at around $t_{5}$, in two separate experiments,

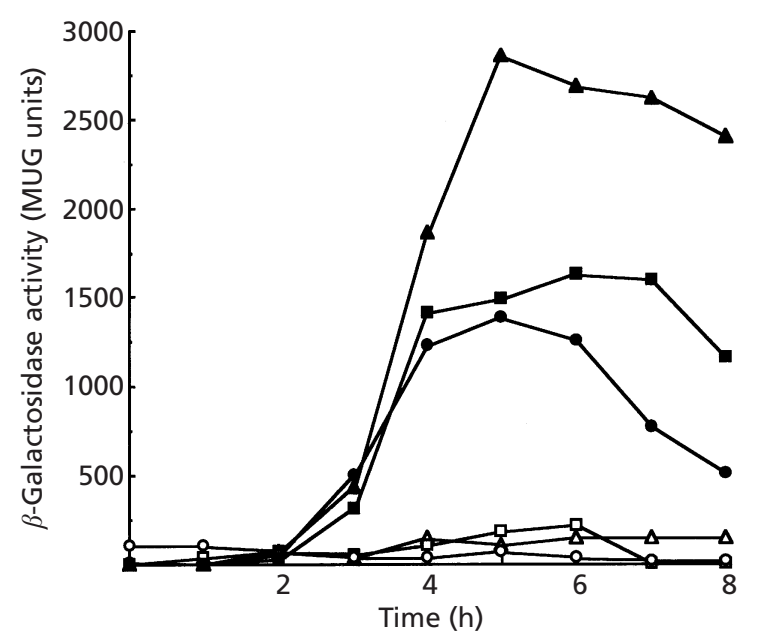

Fig. 3. Timing and the effect of sigma factor mutations on sle $B-l a c Z$ expression during sporulation. $\beta$-Galactosidase levels were measured following induction of synchronous sporulation in strains $\mathrm{FB} 101(s / e B, 0)$ and $\mathrm{FB} 102(y p e B, \square)$ and various sigma factor mutant background strains [FB103 (sigE, $\triangle$ ); FB104 $(\operatorname{sig} F, \bigcirc) ; \mathrm{FB} 105(\operatorname{sig} G, \square)$ and FB106 $(\operatorname{sigK}, \mathbf{\Delta})]$.

suggesting that the operon is regulated by a sporulationspecific sigma factor (Fig. 3). The time of induction of both $s l e B$ and $y p e B$ correspond well with the published data for genes regulated by $\sigma^{G}$ (Setlow, 1989). An apparent decrease in LacZ activity after $t_{5}$ of sporulation has been observed in experiments using fusions to forespore-specific genes such as gdh and gerA (Mason et al., 1988; Feavers et al., 1990) and is due to the progressive increase in resistance of the developing forespore to lysozyme used in the assay.

Chromosomal DNA carrying the sleB-lacZ fusion was transferred by transformation into strains carrying various spo mutations and $\beta$-galactosidase was measured during sporulation. The absence of expression of sleB-lacZ in strain FB105 carrying a mutation in the 


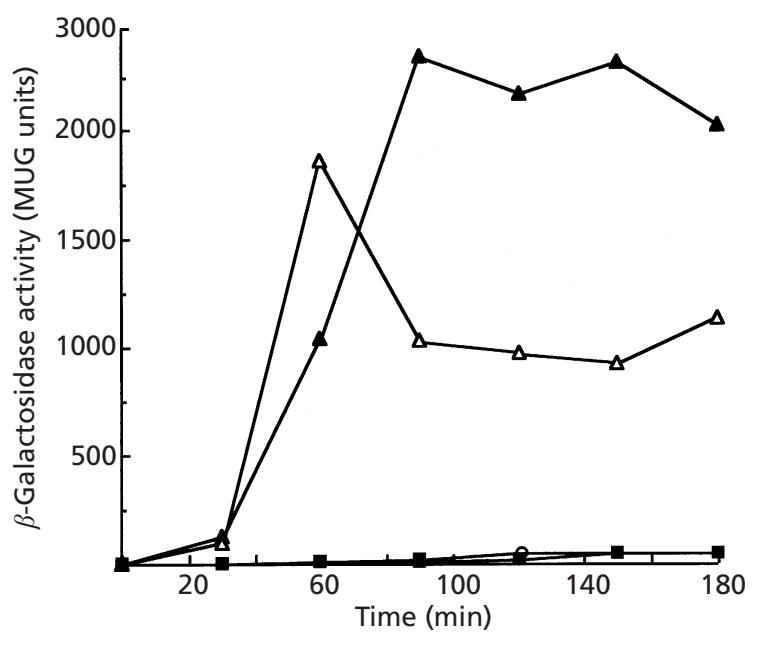

Fig. 4. Expression of $s / e B-l a c Z$ in strains carrying various sporulation-specific sigma factors under Pspac promoter control during vegetative growth. Strain FB103 (Pspac-sigF, O), FB104 (Pspac-sigE, $\triangle$ ), FB105 (Pspac-sigG, $\Delta$ ) and FB106 (Pspac-sigK, - were grown in L-broth and induced by the addition of IPTG to a final concentration of $1 \mathrm{mM}$. At various times, samples $(1 \mathrm{ml})$ were harvested, treated with lysozyme and assayed for $\beta$ galactosidase activity.

spoIIIG gene $\left(\sigma^{\mathrm{G}}\right)$ but still containing an intact spoIIGB gene $\left(\sigma^{\mathrm{E}}\right)$ indicates that $\sigma^{\mathrm{G}}$ is required for the in vivo expression of sleB-lacZ. Expression was blocked in strain FB104 by an inactivation of the spoIIABC $\left(\sigma^{\mathrm{F}}\right)$ operon, as expected, since this sigma factor is required for subsequent expression of other sigma factors during sporulation. As found previously with a number of forespore-specific genes (Setlow, 1989; Mason et al., 1988), lacZ expression was not blocked by a mutation in the spoIIIC gene (strain FB106) required for $\sigma^{\mathrm{K}}$ expression which regulates mother-cell-specific gene expression (Fig. 3).

To test the sigma-factor specificity of RNA polymerase which could transcribe the sleB gene, the sleB-lacZ fusion was introduced by transformation into strains FB107, FB108 and FB109 (Table 1), which contain plasmids having Pspac-inducible genes encoding spoIIGB $\left(\sigma^{\mathrm{E}}\right)$, spoIIAC $\left(\sigma^{\mathrm{F}}\right)$ and spoIIIG $\left(\sigma^{\mathrm{G}}\right)$, respectively (Popham \& Stragier, 1991; Oke \& Losick, 1993; Sun et al., 1989). The sleB-lacZ fusion was also introduced into strain FB110, which contains a chromosomally located $\sigma^{\mathrm{K}}$ coding sequence under Pspac control.

Expression of $\beta$-galactosidase activity was detected on induction of $\sigma^{\mathrm{G}}$, showing that production of $\sigma^{\mathrm{G}}$ is sufficient to direct expression from the sle $B$ promoter (Fig. 4). A putative consensus sequence for $\sigma^{\mathrm{G}}$ binding is detectable upstream of the transcriptional start site of sleB. Expression of $\beta$-galactosidase did not occur following induction of $\sigma^{\mathrm{K}}$ or $\sigma^{\mathrm{F}}$, but expression was detected after induction of $\sigma^{\mathrm{E}}$ in vegetative cells, in three separate experiments (Fig. 4). No expression of sleBlacZ was observed in vivo in a spoIIIG mutant, which would contain functional $\sigma^{\mathrm{E}}$. The expression in veg- etative cells in response to $\sigma^{\mathrm{E}}$ induction may be artefactual, or may reflect further levels of regulation.

\section{DISCUSSION}

Recent analysis of B. subtilis and B. megaterium cortex hydrolysis during germination has revealed a complex common process involving at least three hydrolytic enzymes; an $\mathrm{N}$-acetylglucosaminidase, a lytic transglycosylase and a possible amidase (Atrih \& Foster, 1999; Atrih et al., 1998, 1999). Another activity, suggested to be an epimerase, produces muropeptides with longer retention times than their counterparts in dormant spores. This activity has been extracted from germinated spores of B. megaterium along with an $\mathrm{N}$ acetylglucosaminidase (Atrih et al., 1999). In this study, we analysed the role of $s l e B$ and $y p e B$, which form a bicistronic operon (Moriyama et al., 1999) involved in cortex hydrolysis. sle $B$ has been previously insertionally inactivated in B. subtilis and was shown to be a crucial gene in germination (Moriyama et al., 1996a). Peptidoglycan analysis of the spore-associated material of strain FB101 after 2 h germination revealed a partial hydrolysis of peptidoglycan. More interestingly, the analysis of the muropeptides in the germination exudate showed a major difference compared to that of the wild-type. The anhydromuropeptides generated by the lytic transglycosylase (Atrih et al., 1998) were absent in the exudate, indicating that the gene may encode the lytic transglycosylase. Mutant spores release approximately $20 \%$ less peptidoglycan material than the wild-type and the spores remain phase-grey $12 \mathrm{~h}$ after addition of $\mathrm{L}$ alanine. These observations indicate the crucial role of the enzyme and demonstrate that it is probably acting on spore-associated material as well as peptidoglycan fragments as previously suggested (Atrih et al., 1998). Another interesting feature of the germination exudate of FB101 $(s l e B)$ is the increase of $N$-acetylglucosaminidase products. The $\mathrm{N}$-acetylglucosaminidase was previously thought to have only a minor role in cortex hydrolysis during germination of $B$. subtilis (Atrih et al., 1998). In B. megaterium KM, an extract from germinating spores contains primarily $\mathrm{N}$ acetylglucosaminidase activity and is able to cause germination-like changes in permeabilized spores of $B$. subtilis and B. megaterium (Atrih et al., 1999). The increase in $\mathrm{N}$-acetylglucosaminidase activity may compensate for the absence of lytic transglycosylase, since both enzymes cleave glycan strands. Spore cortex is loosely cross-linked, links occurring at only $2.9 \%$ of muramic acid residues (Atrih et al., 1996). This conserved spore peptidoglycan structural feature suggests that cleavage of relatively few bonds in the cortex may result in the mechanical constraint being removed (Atrih \& Foster, 1999). The fact that Nacetylglucosaminidase is only able to achieve partial hydrolysis of peptidoglycan suggests a co-operative action of the different GSLEs. It is possible that the glucosaminidase may have specific requirements and only cleaves at specific locations. The sleB gene was suggested to code an amidase by analogy to the gene in 
B. cereus (Moriyama et al., 1996a, 1999). However, our present result indicates that it is likely to be a lytic transglycosylase. Recent findings did not show an amidase activity in the form of amidase products during cortex hydrolysis of B. subtilis (Atrih et al., 1998).

The sleB gene is the first in the operon and its inactivation is likely to have an effect on the downstream gene, $y p e B$. Insertion inactivation of $y p e B$ or in-frame deletion of sleB produced mutants with similar germination defects. This indicates that both genes are necessary for cortex hydrolysis during germination and therefore are essential for the activity of the lytic transglycosylase encoded by sleB. SleB has recently been shown to be located just inside the spore coat layer in the dormant spore and to exist in mature form but lacking a signal sequence (Moriyama et al., 1999). The enzyme is translocated across the forespore's inner membrane by a secretion signal peptide and is deposited in cortex layer synthesized between the forespore inner and outer membrane (Moriyama et al., 1999).

The role of YpeB is still unclear. It appears to be required for either expression, localization, activation or function of SleB. The N-terminal region of $\mathrm{YpeB}$ could represent a hydrophobic anchor for the localization of the protein in the membrane or a signal peptide sequence involved in the translocation of the protein across the membrane. The ypeB gene has homologues in B. cereus and B. megaterium KM, all in the same operon organization, downstream of a sle $B$ homologue. In B. cereus, the gene corresponding to ypeB encodes a protein that has $75 \%$ identity to YpeB from $B$. subtilis (Moriyama et al., 1996b) and the equivalent gene in B. megaterium $\mathrm{KM}$ encodes a protein having $65 \%$ identity (Pettigrew, 1996). These data suggest that $y p e B$ may have the same role in $B$. cereus and $B$. megaterium as in B. subtilis.

There are two more homologues of SleB in B. subtilis, CwlJ and YkvT, which exhibit $28 \%$ and $30 \%$ identity, respectively, with the putative catalytic C-terminal domain of SleB. CwlJ, like SleB, is involved in the later stages of germination (Ishikawa et al., 1998), although its effects are less pronounced. The double mutant sleB cwlJ is blocked completely in later germination so that colony formation is not possible. Interestingly, the lack of cortex hydrolysis does not affect the loss of optical density or dipicolinic acid release, indicating that cortex hydrolysis and release of small solutes during germination are probably two separate events (Sekiguchi et al., 1995; Atrih et al., 1996, 1998; Popham et al., 1996b). However, unlike sleB, cwlJ and $y k v T$ do not occur in an operon with a homologue of $y p e B$. The observation that the phenotype of the sleB or $y p e B$ mutants are identical suggests that $y p e B$ is not involved in the expression or the function of cwlJ. The genes sleB and cwlJ differ in their compartment-specific regulation during sporulation; cwlJ is transcribed by $\mathrm{E} \sigma^{\mathrm{E}} \mathrm{RNA}$ polymerase in the mother cell (Ishikawa et al., 1998), and this work demonstrates that sleB expression is dependent on $\sigma^{\mathrm{G}}$, a forespore-specific sigma factor. Expression of sleB has also recently been shown to be controlled by $\sigma^{\mathrm{G}}$ using primer extension analysis (Moriyama et al., 1999).

The mechanism of SleB and CwlJ activation and their molecular interplay, as an integral part of the germination triggering response, is currently under investigation.

\section{ACKNOWLEDGEMENTS}

We thank Professor J. Errington for the provision of strains and Dr M. J. Horsburgh for helpful advice. We would also like to thank Dr G. Allmaier and G. Bacher for MS analysis. This work was supported by the BBSRC (A.A. and H.C.), the European Community (HCM grant ERB CHRX CT950278) and the Royal Society (S. J.F).

\section{REFERENCES}

Anagnostopoulos, C. \& Spizizen, J. (1961). Requirements for transformation in Bacillus subtilis. J Bacteriol 81, 741-746.

Atrih, A. \& Foster, S. J. (1999). The role of peptidoglycan structure and structural dynamics during endospore dormancy and germination. Antonie Leeuwenhoek 75, 299-307.

Atrih, A., Zöllner, P., Allmaier, G. \& Foster, S. J. (1996). Structural analysis of Bacillus subtilis 168 endospore peptidoglycan and its role during differentiation. J Bacteriol 178, 6173-6183.

Atrih, A., Zöllner, P., Allmaier, G., Williamson, M. P. \& Foster, S. J. (1998). Peptidoglycan structural dynamics during germination of Bacillus subtilis 168 endospores. J Bacteriol 180, 4603-4612.

Atrih, A., Bacher, G., Körner, R., Allmaier, G. \& Foster, S. J. (1999). Structural analysis of Bacillus megaterium KM spore peptidoglycan and its dynamics during germination. Microbiology 145, 1033-1041.

Chen, Y., Miyata, S., Makino, S. \& Moriyama, R. (1997). Molecular characterization of a germination-specific muramidase from Clostridium perfringens S40 spores and nucleotide sequence of the corresponding gene. J Bacteriol 179, 3181-3187.

Ellar, D. J. (1978). Spore specific structures and their function. Symp Soc Gen Microbiol 28, 295-325.

Feavers, I. M., Foulkes, J., Setlow, P., Sun, D., Nicholson, W., Setlow, P. \& Moir, A. (1990). The regulation of transcription of the gerA spore germination operon of Bacillus subtilis. Mol Microbiol 4, 275-282.

Foster, S. J. \& Johnstone, K. (1987). Purification and properties of a germination-specific cortex-lytic enzyme from spores of Bacillus megaterium KM. Biochem J 242, 573-579.

Foster, S. J. \& Johnstone, K. (1988). Germination-specific cortexlytic enzyme is activated during triggering of Bacillus megaterium KM spore germination. Mol Microbiol 2, 727-733.

Hanahan, D. (1983). Studies on transformation of Escherichia coli with plasmids. Mol Biol 166, 557-580.

Ishikawa, S., Yamane, K. \& Sekiguchi, J. (1998). Regulation and characterization of a newly deduced cell wall hydrolase gene $(c w l J)$ which affects germination of Bacillus subtilis spores. J Bacteriol 180, 1375-1380.

Kunst, F., Ogasawara, N., Moszer, I. \& 148 other authors (1997). The complete genome sequence of the Gram-positive bacterium Bacillus subtilis. Nature 390, 249-256.

Makino, S., Ito, N., Inoue, T., Miyata, S. \& Moriyama, R. (1994). A spore-lytic enzyme released from Bacillus cereus spores during germination. Microbiology 140, 1403-1410. 
Mason, J. M., Hackett, R. H. \& Setlow, P. (1988). Regulation of expression of genes coding for small, acid-soluble proteins of Bacillus subtilis spores: studies using lacZ gene fusions. J Bacteriol 170, 239-244.

Miyata, S., Moriyama, R., Miyahara, N. \& Makino, S. (1995). A gene (sleC) encoding a spore-cortex-lytic enzyme from Clostridium perfringens S40 spores; cloning, sequence analysis and molecular characterization. Microbiology 141, 2643-2650.

Moriyama, R., Hattori, A., Miyata, S., Kudoh, S. \& Makino, S. (1996a). A gene (sleB) encoding a spore cortex-lytic enzyme from Bacillus subtilis and response of the enzyme to L-alanine-mediated germination. J Bacteriol 178, 6059-6063.

Moriyama, R., Kudoh, S., Miyata, S., Nonobe, S., Hattori, A. \& Makino, S. (1996b). A germination-specific cortex-lytic enzyme from Bacillus cereus spores: cloning and sequencing of the gene and molecular characterization of the enzyme. J Bacteriol 178, 5330-5332.

Moriyama, R., Fukuoka, H., Miyata, S., Kudoh, S., Hattori, A., Kozuka, S., Yasuda, Y., Tochikubo, K. \& Makino, S. (1999). Expression of a germination-specific amidase, SleB, of Bacilli in the forespore compartment of sporulating cells and its localization on the exterior side of the cortex in dormant spores. J Bacteriol 181, 2373-2378.

Oke, V. \& Losick, R. (1993). Multilevel regulation of the sporulation transcription factor $\sigma^{\mathrm{K}}$ in Bacillus subtilis. J Bacteriol 175, 7341-7347.

Pettigrew, J. R. (1996). Molecular analysis of the germination trigger mechanism of Bacillus megaterium KM. PhD thesis, University of Cambridge.

Popham, D. L. \& Stragier, P. (1991). Cloning, characterization, and expression of the spoVB gene of Bacillus subtilis. J Bacteriol 173, 7942-7949.

Popham, D. L., Helin, J., Costello, C. E. \& Setlow, P. (1996a). Analysis of the peptidoglycan structure of Bacillus subtilis endospores. J Bacteriol 178, 6451-6458.

Popham, D. L., Helin, J., Costello, C. E. \& Setlow, P. (1996b). Muramic lactam in peptidoglycan of Bacillus subtilis spores is required for spore outgrowth but not spore dehydration or heat resistance. Proc Natl Acad Sci USA 93, 15405-15410.

Sambrook, J., Fritsch, E. F. \& Maniatis, T. (1989). Molecular Cloning: a Laboratory Manual, 2nd edn. Cold Spring Harbor, NY: Cold Spring Harbor Laboratory.
Scott, I. R. \& Ellar, D. J. (1978). Study of calcium dipicolinate release during bacterial spore germination by using a new, sensitive assay for dipicolinate. J Bacteriol 135, 133-137.

Sekiguchi, J., Akeo, K., Yamamoto, H., Khasnov, F. K., Alonso, J. C. \& Kuroda, A. (1995). Nucleotide sequence and regulation of a new putative cell wall hydrolase gene, cwlD, which affects germination in Bacillus subtilis. J Bacteriol 177, 5582-5589.

Setlow, P. (1989). Forespore-specific genes of Bacillus subtilis: function and regulation of expression. In Regulation of Prokaryotic Development, pp. 211-221. Edited by I. Smith, R. A. Slepecky \& P. Setlow. Washington, DC: American Society for Microbiology.

Sterlini, J. M. \& Mandelstam, J. (1969). Commitment to sporulation in Bacillus subtilis and its relationship to development of actinomycin resistance. Biochem J 113, 29-37.

Stewart, G. S. A. B., Johnstone, K., Hagelberg, E. \& Ellar, D. J. (1981). Commitment of bacterial spores to germinate. Biochem J 198, 101-106.

Sun, D., Stragier, P. \& Setlow, P. (1989). Identification of a new $\sigma$ factor involved in compartmentalized gene expression during sporulation of Bacillus subtilis. Genes Dev 3, 141-149.

Turner, S. M., Errington, J. \& Mandelstam, J. (1986). Use of a lacZ gene fusion to determine the dependence pattern of sporulation operon spoIIIC in spo mutants of Bacillus subtilis: a branched pathway of expression of sporulation operons. J Gen Microbiol 132, 2995-3003.

Vagner, V., Dervyn, E. \& Ehrlich, S. D. (1998). A vector for systematic gene inactivation in Bacillus subtilis. Microbiology 144, 3097-3104.

Youngman, P. (1990). Use of transposons and integrational vectors for mutagenesis and construction of gene fusions in Bacillus species. In Molecular Biology Methods for Bacillus, pp. 221-266. Edited by C. R. Harwood \& S. M. Cutting. New York: Wiley.

Zuberi, A. R., Moir, A. \& Feavers, I. M. (1987). The nucleotide sequence and gene organization of the gerA spore germination operon of Bacillus subtilis 168. Gene 51, 1-11.

Received 27 August 1999; revised 20 September 1999; accepted 23 September 1999. 